\title{
9 Feedback for learning
}

\author{
Cameron Brooks, Rochelle Burton, and \\ John Hattie
}

\section{How to use this policy}

Feedback is a critical process of learning that is shaped by many factors including school culture, curriculum, assessment, and pedagogy (Black \& Wiliam, 2018; Hattie \& Clarke, 2019). This policy example is intentionally broad and school policy creators are encouraged to delete and build upon suggestions below to create a policy that best represents their school. A school policy on feedback is best formed through consultation with key stakeholders in the feedback process: students, teachers, and parents. Feedback policy is ideally adopted at the whole of school level with direct communication with the school community (i.e., parents) to help develop a culture of learning that is underpinned by effective feedback processes. Furthermore, whole school feedback policy should seek to make explicit the connections between feedback and curricula, assessment, and pedagogy. Feedback policy should aim to inform teachers about how to use feedback effectively in the classroom. To evaluate policy impact, schools should implement processes that make both learning success and learning progress visible.

[To adapt and use this policy, delete or modify the text as indicated]

\section{[INSERT name of school] Feedback for learning}

\section{Rationale}

Feedback is one of the most powerful processes used by teachers to influence learning (Hattie, 2009). Feedback has been credited with high effect sizes on student achievement (Hattie, 2009) and is seen as instrumental in improving student learning outcomes. The power of feedback, however, cuts both ways with highly variable effects recorded (Kluger \& DeNisi, 1996). This means that feedback can have highly positive effects upon learning but also highly negative effects where students may, in fact, be turned off learning - indeed a major review showed that about one-third of feedback can be negative (Kluger \& DeNisi, 1996). School leaders and teachers need to be aware of the conditions and variables that make feedback effective for students and therefore conducive to learning improvement. 
Feedback is effective when it: (i) clarifies success; (ii) informs the learner of progress relative to success; (iii) offers guidance about the next steps to improve; and (iv) when it is received, understood, and actionable (Hattie \& Timperley, 2007). Effective feedback processes should cause thinking with the aim of feedback interpretation leading to improvement. The responsibility and effort associated with giving of, receiving of, and acting on feedback needs to be shared between students, peers, and teachers (Wiliam, 2016). Best practice engages the learner as an active agent in the feedback process; that is, the recipient of feedback (such as the student or the teacher) needs to listen, interpret, and make decisions about reacting to the feedback (Jónsson \& Panadero, 2018). The effectiveness of feedback is a function of the quality, timing, and information value for the giver and the receiver. Teachers acting as facilitators of feedback should aim to develop sustainable feedback practices such as active review and critique to help build students' nose for quality (Claxton, 1995; Sadler, 2010). Teachers should also review their own practice and seek feedback to help improve their impact on their students (Hattie, 2012).

\section{Purpose}

The purpose of this policy is to outline key conditions and practices that are conducive to effective and sustainable feedback practices.

\section{Scope}

This policy applies to the students, teachers, school leaders. and parents of [INSERT school name]. [INSERT specific roles and responsibilities of individuals or teams]

\section{Policy statement}

\section{A culture of learning}

[INSERT name of school] views feedback as a fundamental process to improve student learning outcomes. Feedback needs to be just in time, aimed at the level of the learner, and aimed to improve the curiosity and effectiveness of learning (Hattie, Gan, \& Brooks, 2016). Our school creates a culture in which feedback is sought and welcomed.

At [INSERT name of school] we believe that effective feedback aims to improve the learner rather than simply fix the work. Students at our school are aware that feedback requires effortful engagement to receive, interpret, and act on the feedback message, and that this is a regular part of learning.

Errors, mistakes, or misconceptions are seen as part of learning at [INSERT name of school], and are seen as opportunities for improvement. We acknowledge that feedback feeds on errors. Our students know they may not 
be successful at their first attempt and effective feedback processes can guide them toward their next steps.

[INSERT name of school] is committed to putting in place development for any members of the school community to broaden their knowledge or skills in delivering and receiving effective feedback and thus creating a culture of learning.

Our students and teachers are familiar with protocols on giving, seeking, and receiving feedback such as directing the focus of feedback to the work, not the self/person (Boud, 2015).

\section{Review practice}

[INSERT name of school] implements practices such as collaborative planning with teachers and school leaders to develop a shared understanding of the learning intent and success criteria (Hattie \& Clark, 2019).

Backward mapping from summative evaluations is a process used to formulate formative assessment opportunities to elicit evidence of student learning and progress.

Formative assessment meetings are scheduled with teachers and school leaders to review their impact on students, using evidence of learning from the whole class as opposed to a few selected student samples (Hattie, 2012).

\section{Clarify success}

At [INSERT name of school] we make the learning intent and success criteria visible and appropriately challenging for students so they know what they are working toward (Hattie, 2012).

Teachers at [INSERT name of school] co-construct success criteria with students by using an active critiquing process where students deconstruct and evaluate aspects of stronger and weaker models, responses, and work samples (Lee, Mak, \& Yuan, 2019).

Students are actively involved in mapping the success criteria to models or exemplars to help visualise success (Berger, Rugen, \& Woodfin, 2014).

At [INSERT name of school] we believe that students can demonstrate learning by transferring knowledge and skills from one context to another, hence, models used in class must be different to the specific context or questions of the summative evaluations.

\section{Check in on progress}

At [INSERT name of school] we do not grade formative assessment as grades can interfere with the feedback message, but we do provide the student with specific information about how to improve (Shute, 2008).

Our teachers use informal and formal methods of formative assessment to gauge where students are at in relation to the success criteria and learning 
intent. The use of low-stakes pre-assessment at the start of, or early in the learning period to ascertain student prior knowledge is a process at [INSERT name of school] to maximise the window of opportunity for improvement.

School leaders at [INSERT name of school] support teachers both inside and outside of the classroom to develop effective formative assessment practices and questions.

Our teachers view ongoing student formative assessment and summative evaluation responses not only as evidence of student learning progress but also as a reflection of their teaching impact.

Students at [INSERT name of school] see formative assessment as an opportunity to receive improvement-based feedback rather than a process of examination. Hence, our students have an expectation they will be engaged in feedback processes throughout their learning.

\section{Promoting improvement}

[INSERT name of school] allocates resources that allow teachers to collaborate and review evidence of student learning from formative assessments with the aim of making decisions about the next steps for teaching and subsequent student improvement.

Our teachers understand the importance of activating students in feedback and instigate processes such as critiquing of stronger and weaker work samples and peer review prior to students engaging in self-review of their own work.

Students at [INSERT name of school] are taught to receive feedback (whether that be self, peer, or from a teacher) about how to improve in time to act on this feedback to improve learning outcomes (Brookhart, 2017).

Feedback at [INSERT name of school] includes both information about what to improve and guidance about how to improve.

\section{Authorship}

Dr Cameron Brooks, University of Queensland

Rochelle Burton, University of Queensland

Professor John Hattie, University of Melbourne

[INSERT RELEVANT STAFF MEMBERS]

\section{Related policy and documents}

\section{[INSERT RELEVANT POLICY AND DOCUMENTS]}

Australian Institute for Teaching and School Leadership (AITSL): Effective Feedback for Schools https://www.aitsl.edu.au/docs/default-source/researchevidence/spotlight/spotlight-feedback.pdf?sfvrsn=cb2eec3c_12 


\section{Rating of evidence base}

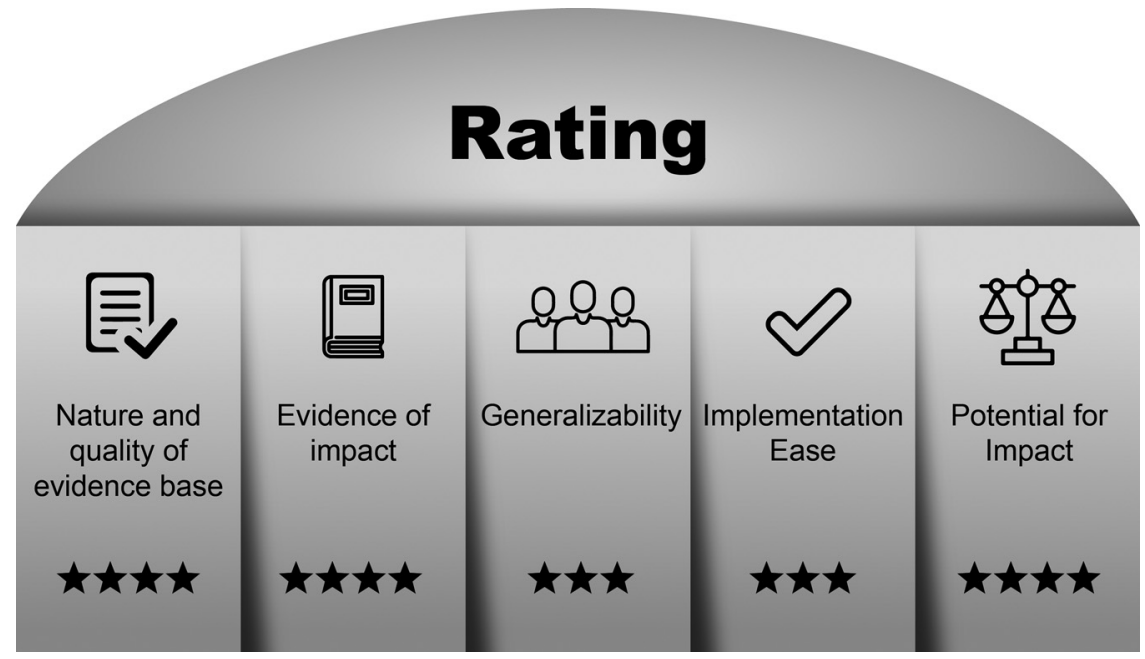

Figure 9.1. Feedback for Learning Rating of Evidence.

Author Note. The policy is built from a body of work with a substantial evidence base with a low risk of bias that could be considered to be of adequate quality. There are some reviews that question the dependent and independent variables used in feedback meta-analyses and whether negative effects are consistently reported (Kluger \& DeNisi, 1996). The research evidence used in the policy demonstrates high levels of impact with high effect sizes recorded (Hattie, 2009). The research used within the policy provides substantial evidence for generalisability to the broader population. Feedback pedagogy is an integral component of all aspects of teaching and learning. Feedback, formative assessment, and assessment for learning are regarded as relatively low-cost and lowresource initiatives that can be implemented by the teaching and school leadership teams (Higgins, Katsipataki, Villanueva-Aguilera, Coleman, Henderson, Major, \& Mason, 2016). Resource consideration may need to be given to teacher release. There is excellent potential for impact from this policy. Teaching practice can be enhanced as teachers will develop deeper understandings of the criteria for success and evidence of student learning. Students have the potential to become more actively engaged and self-regulated (Hattie, 2012).

\section{Date of ratification}

This policy was ratified on the [INSERT DATE].

\section{Date of review}

This policy will be reviewed by [INSERT DATE]. 


\section{Further reading}

Hattie, J., \& Clarke, S. (2019). Visible learning: Feedback. New York: Routledge.

\section{References}

Berger, R., Rugen, L., \& Woodfin, L. (2014). Leaders of their own learning: Transforming schools through student-engaged assessment. San Francisco: Wiley.

Black, P., \& Wiliam, D. (2018). Classroom assessment and pedagogy. Assessment in Education: Principles, Policy \& Practice, 25(6), 551-575.

Boud, D. (2015). Feedback: Ensuring that it leads to enhanced learning. Clinical Teacher, 12(1), 3-7.

Brookhart, S. M. (2017). How to give effective feedback to your students. Alexandria, VA: Association for Supervision and Curriculum Development.

Claxton, G. (1995). What kind of learning does self-assessment drive? Developing a "nose" for quality: comments on Klenowski (1995). Assessment in Education: Principles, Policy \& Practice, 2(3), 339-343.

Hattie, J. (2009). Visible learning: A synthesis of over 800 meta-analyses relating to achievement. Abingdon: Routledge.

Hattie, J. (2012). Visible learning for teachers: Maximizing impact on learning. New York: Routledge.

Hattie, J., \& Clarke, S. (2019). Visible learning: Feedback. New York: Routledge.

Hattie, J., Gan, M., \& Brooks, C. (2016). Instruction based on feedback. In R. E. Mayer, \& P. A. Alexander (Eds.), Handbook of research on learning and instruction. New York: Routledge.

Hattie, J., \& Timperley, H. (2007). The power of feedback. Review of Educational Research, 77(1), 81-112. Thousand Oaks, CA: SAGE.

Higgins, S., Katsipataki, M., Villanueva-Aguilera, A. B., Coleman, R., Henderson, P., Major, L. E., \& Mason, D. (2016). The Sutton Trust-Education Endowment Foundation teaching and learning toolkit. London: Education Endowment Foundation. http://www.educationendowmentfoundation.org.uk/toolkit

Jónsson, A., \& Panadero, E. (2018). Facilitating students' active engagement with feedback. In A. Lipnevich \& J. Smith (Eds.), The Cambridge handbook of instructional feedback, (pp. 531-553). Cambridge: Cambridge University Press.

Kluger, A. N., \& DeNisi, A. (1996). The effects of feedback interventions on performance: A historical review, a meta-analysis, and a preliminary feedback intervention theory. Psychological Bulletin, 119(2), 254-284.

Lee, I., Mak, P., \& Yuan, R. E. (2019). Assessment as learning in primary writing classrooms: An exploratory study. Studies in Educational Evaluation, 62, 72-81.

Sadler, D. R. (2010). Beyond feedback: Developing student capability in complex appraisal. Assessment \& Evaluation in Higher Education, 35(5), 535-550.

Shute, V. J. (2008). Focus on formative feedback. Review of Educational Research, 78(1), 153-189.

Wiliam, D. (2016). The secret of effective feedback. Educational Leadership, 73(7), 10-15. 